\title{
Populismo en España: Fundamentos Teóricos y Relatos Dominantes
}

\section{Populism in Spain: Theoretical Foundations and Dominant Narratives}

\section{José Javier Olivas Osuna ${ }^{1}$ \\ Universidad Nacional de Educación a Distancia (España) The London School of Economics and Political Science (LSE)}

ORCID: https://orcid.org/0000-0002-9877-8480

Recibido: 20-04-2021

Aceptado: 12-06-2021

\section{Resumen}

El populismo se ha convertido en uno de los fenómenos políticos que más preocupan y, dada su complejidad, uno de los más controvertidos y debatidos actualmente en las ciencias sociales. Este artículo deconstruye y compara los discursos de los partidos políticos españoles que generalmente son clasificados como populistas -el izquierdista Podemos, el derechista Vox y los partidos secesionistas vascos y catalanes, EH Bildu, Esquerra Republicana de Catalunya y Junts per Catalunya- de acuerdo a cinco dimensiones del populismo: i) antagonismo, ii) moralidad, iii) construcción idealizada de la sociedad, iv) exaltación de la soberanía popular, y v) liderazgo personalista. Este artículo

\footnotetext{
${ }^{1}$ (jjolivas@poli.uned.es / j.j.olivas-osuna@1se.ac.uk). José Javier Olivas Osuna dirige un proyecto interdisciplinar comparativo sobre populismo y secesionismo en el Departamento de Ciencia Política y de la Administración de la UNED (Madrid) y es Investigador Asociado a LSE IDEAS y Cañada Blanch Centre en LSE. Es doctor en Gobierno y Máster en Políticas Públicas y Administración por LSE. José Javier también se licenció en Ciencias Económicas y Empresariales y en investigación de Mercados (ETEA, Córdoba), y realizó un postgrado en estudios europeos (EDHEC, Lille). Es en la actualidad beneficiario del programa de atracción de talento investigador modalidad senior de la Comunidad de Madrid. Sus áreas de investigación incluyen populismo, políticas públicas, Brexit y relaciones civiles-militares. Entre sus publicaciones destacan: "From chasing populists to deconstructing populism: a new multidimensional approach to understanding and comparing populism" (2021), en European Journal of Political Research; "Place matters: analyzing the roots of political distrust and Brexit narratives at a local level" (2021), en Governance (con Kiefel M. \& Gartzou-Katsouyanni K.); y la monografía Iberian Military Politics: Controlling the Armed Forces During Dictatorship and Democracy (2014) publicada por Palgrave Macmillan.
} 
muestra que, a pesar de las significativas diferencias ideológicas y programáticas, todos estos partidos comparten muchos rasgos discursivos y una manera similar de articular sus comunicaciones, interpretar las dinámicas sociales y políticas, así como de instrumentalizar las crisis para construir nuevas identidades políticas.

Palabras-clave: populismo, nacionalismo, discursos, partidos políticos, política española

\begin{abstract}
Populism has become one of the most worrying political phenomena, and given its complexity, one of the most controversial and debated today in social sciences. This article deconstructs and compares the discourses of the Spanish parties that are generally classified as populist -the left-leaning Podemos, the right-wing Vox and the Basque and Catalan secessionist parties EH Bildu, Esquerra Republicana de Catalunya and Junts per Catalunyaaccording to five dimensions of populism: i) antagonism, ii) morality, iii) idealised construction of society, iv) exaltation of popular sovereignty, and v) personalist leadership. This article shows that, despite significant ideological and programmatic differences, all these parties share many discursive features and a similar way of articulating their communications, interpreting social and political dynamics, as well as instrumentalizing crises to build new political identities.
\end{abstract}

Keywords: populism, nationalism, discourses, political parties, Spanish politics

\title{
Introducción
}

El populismo es uno de los mayores retos a afrontar por parte de las democracias pluralistas occidentales (Kriesi et al. 2008; Müller 2014) y un fenómeno con cada vez más trascendencia en España. Este artículo compara las características discursivas de los partidos políticos españoles comúnmente clasificados como populistas para establecer si, a pesar de la distancia ideológica que los separa, comparten un núcleo de atributos comunes. Primero se hace referencia a la cada vez mayor relevancia del estudio del populismo en el mundo académico y la diversidad de movimientos que cubre. A continuación, se introduce brevemente la evolución reciente de este fenómeno en España, y en particular los tres casos analizados: el populismo de izquierda de Podemos, el de derecha de Vox y el de los partidos secesionistas vascos y catalanes, este último más difícil de situar en el eje izquierda-derecha. Después, se esbozan las principales conceptualizaciones y escuelas en esta área de investigación, 
mostrando los matices y las sinergias entre estas. El análisis comparativo de este artículo se divide en cinco subsecciones que se corresponden con cada una de las dimensiones en las que se puede deconstruir este complejo fenómeno: i) antagonismo, ii) moralidad, iii) construcción idealizada de la sociedad, iv) exaltación de la soberanía popular, y v) liderazgo personalista (Olivas Osuna 2021). Finalmente, se establecen unas conclusiones que sintetizan las principales similitudes y divergencias encontradas en los diferentes movimientos populistas.

\section{Populismo, un concepto de moda}

Con la llegada del siglo XXI el concepto de populismo empezó a adquirir centralidad en los debates politológicos y sociológicos gracias a las aportaciones de un grupo destacado de autores, como Margaret Canovan, Ernesto Laclau, Chantal Mouffe, Cas Mudde, Kenneth Roberts, Paul Taggart y Kurt Weyland, entre otros. Este renovado interés académico se justifica por el peso cada vez mayor de los discursos e ideas populistas en las dinámicas políticas, en lo que se ha llegado a denominar como un "Zeitgeist populista" (Mudde 2004) o "momento populista” (Mouffe 2018). Además, este fenómeno no quedó confinado al dominio político, sino que los argumentos populistas han ocupado cada vez más espacio en los medios de comunicación (Hameleers y Vliegenthart 2020). En la segunda década del siglo el interés académico se disparó y se multiplicaron las publicaciones, conferencias y seminarios sobre el tema. Mientras en 2010 se publicaron 77 artículos con las palabras "populism" o "populist" en el título, en 2020 este número había ascendido a 860². La utilización del término populismo ha crecido de una forma significativa, hasta el punto de que fue elegida palabra del año en español por Fundeu BBVA, en $2016^{3}$, y en inglés por el Diccionario de Cambridge, en $2017^{4}$.

\footnotetext{
${ }^{2}$ Búsqueda en directorio Web of Science, 30 marzo 2021, todas las publicaciones en todos los idiomas.

${ }^{3}$ El País, 'Populismo', palabra del año para la Fundéu BBVA, 30 diciembre 2016.

${ }^{4}$ University of Cambridge, 'Populism' revealed as 2017 Word of the Year by Cambridge University Press, 30 noviembre 2017.
} 
Gráfico 1: Número de artículos académicos publicados con los términos "populism" o "populist"

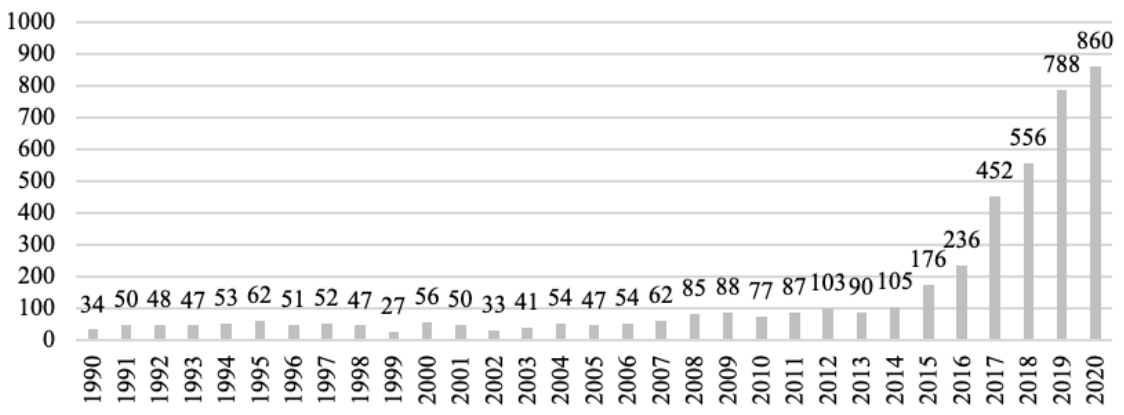

Fuente: Elaboración propia basado en datos de Web of Science

A pesar del reciente auge, el origen de este campo de estudio se remonta unas décadas en el tiempo. En 1967 tuvo lugar en The London School of Economics and Political Science (LSE) el primer encuentro internacional sobre populismo titulado "To Define Populism". En aquellas jornadas, intelectuales de la talla de Isaiah Berlin, Ernest Gellner y Richard Hofstadter, entre muchos otros, debatieron sobre la conceptualización de este complejo término y la gran diversidad de movimientos políticos que abarcaba. Se trataron casos como el de los Narodniks rusos, que surgieron como reacción al desarrollo del capitalismo, o el populismo agrario norteamericano, que se oponía a los grupos financieros y grandes corporaciones, ambos de finales del siglo XIX. También se cubrieron los populismos del siglo XX en América Latina, que se enfrentaban a la oligarquía; los africanos, que a menudo dirigían líderes mesiánicos en el gobierno pero exaltaban a la gente corriente, y los populismos asiáticos que idealizaban la vida rural en oposición al individualismo occidental (Berlin 1968: 138-155).

A estos populismos históricos hay que sumar nuevos grupos surgidos en la segunda mitad del XX, como por ejemplo la nueva ola de populismo latinoamericano (de la Torre 2010), el populismo personalista de la India (Jaffrelot y Tillin 2017), los partidos Euroescépticos de derecha (Pirro et al. 2018), los populismos de izquierda del sur de Europa (Ramiro y Gómez 2017), los secesionistas (Zaslove 2011; Barrio et al. 2018) o el "Trumpismo" (Lebow 2019). La aparición de nuevos partidos y movimientos y el giro populista de otros existentes previamente se aceleró a partir de los años 90 en diferentes partes del mundo (Mudde 2004: 548-551; Roberts 2007). Como este artículo muestra más adelante, a pesar de la heterogeneidad en cuanto a estrategias electorales, estilos de comunicación e ideologías, estos partidos y sus líderes 
son considerados populistas por compartir una lógica de articulación, estilo comunicativo y una serie de actitudes comunes.

\section{Nueva ola de populismo en España}

En España, hay que buscar el origen de la actual ola de populismo en la crisis económica financiera de 2008. El malestar generado por las políticas de austeridad del gobierno español y el fuerte aumento del desempleo sirvieron como catalizador para que surgiese en 2011 el movimiento de los Indignados o 15-M, en referencia a las masivas manifestaciones que se organizaron a la vez en muchas ciudades españolas el 15 de mayo de ese año. Este movimiento de protesta, inspirado por el ensayo del diplomático francés Stéphane Hessel "Indignez-vous!" (Hessel 2011), se autodefinió como opuesto a los partidos políticos. Ofrecía una alternativa al status quo en España con un modelo horizontal de participación y cooperación (Prentoulis y Thomassen 2013). Los Indignados aprovecharon para su crecimiento y coordinación internet y las redes sociales (Anduiza et al. 2013). También les ayudó la cobertura de la prensa que, en general, reflejó su carácter pacífico y festivo (Kyriakidou y Olivas Osuna 2017). Este movimiento no sólo se expandió por toda España, sino que fue replicado por grupos similares como los Aganaktismeni ("indignados") en Grecia o el movimiento Occupy en Estados Unidos.

Podemos fue creado en 2014 para tratar de articular políticamente el descontento ciudadano y la crisis de legitimidad que el movimiento de los Indignados había puesto de manifiesto. Los fundadores de este partido, fuertemente influenciados por las ideas de Ernesto Laclau y Chantal Mouffe, además de por sus experiencias personales trabajando como asesores e investigadores para gobiernos populistas latinoamericanos como el de Evo Morales, Rafael Correa y Hugo Chávez, decidieron adoptar un discurso y estrategia populista (Gómez-Reino y Llamazares 2019; De Nadal 2020). Inicialmente, Podemos buscaría fomentar una nueva identidad colectiva política más allá de la tradicional división izquierda-derecha enfrentando al "pueblo" - la mayoría, los de abajo- con las élites, la "casta" (Errejón y Mouffe 2016). Sin embargo, poco después adoptaría posiciones abiertamente de izquierda y se asociaría a varios partidos y coaliciones de este signo político para concurrir a elecciones. Dentro de los partidos populistas de izquierda, en España hay que destacar tanto a Más País, escisión de Podemos dirigida por Iñigo Errejón, como a Catalunya en Comú, partido de ámbito autonómico que suele presentarse a las convocatorias electorales en coalición con Podemos.

España fue considerada una excepción dentro de Europa por la ausencia de partidos populistas de derecha radical (Alonso y Rovira-Kaltwasser 2015). 
Sin embargo, el buen resultado electoral de Vox en las elecciones autonómicas andaluzas en diciembre de 2018 marcó el inicio de una trayectoria ascendente de este partido que fue corroborada por los resultados en las dos elecciones generales y autonómicas que siguieron. Vox surgió a finales de 2013, impulsado por ex dirigentes del conservador Partido Popular (PP). A diferencia de otros partidos de derecha radical que normalmente deben su popularidad a discursos y actitudes ciudadanas anti-inmigración, Vox debe en gran medida su impulso a su discurso sobre la unidad territorial de España y en particular a la intensificación del conflicto secesionista en Cataluña (Vampa 2020).

Además de populismos de izquierda y derecha, en España encontramos partidos políticos secesionistas que utilizan argumentos y escenificaciones netamente populistas (Newth 2021). Históricamente había sido la izquierda Abertzale, y en particular Euskal Herria Bildu, la que con más vehemencia mantuvo discursos contra las élites y el establishment, basados en una mitificación del pasado y exaltación de la soberanía del pueblo vasco. Sin embargo, a partir de 2010, el nacionalismo catalán sufrió una transformación y no sólo abrazó mayoritariamente el independentismo, sino también una lógica de articulación y un estilo performativo populista con espectaculares movilizaciones, consultas populares y constantes alusiones a la unidad del pueblo catalán contra las élites españolas (Barrio et al. 2018). Junto a partidos como Esquerra Republicana de Catalunya, Junts per Catalunya (JxCat) y Candidatura d'Unitat Popular (CUP), es importante mencionar organizaciones sociales como la Assemblea Nacional Catalana (ANC) y Òmnium Cultural, que también participan activamente de la vida política y han adoptado una retórica populista. En las siguientes secciones se discuten las similitudes y diferencias en el discurso de estos diferentes movimientos populistas.

La coexistencia en España de diversos populismos, de izquierda, derecha y secesionistas, parece confirmada por los estudios comparativos más importantes realizados sobre el tema, como son el Global Party Survey (Norris 2020) y el Populism and Political Parties Expert Survey (Maurits y Zaslove 2020). Éstos evalúan como alto el nivel de populismo de Podemos, Vox y los partidos independentistas (ver Gráficos 2 y 3 ). Aunque obtienen puntuaciones bajas en dichos índices, cabe recordar que el resto de partidos - PP, PSOE y Ciudadanos-, aunque no son objeto de análisis en este artículo, también utilizan una retórica populista en ciertos contextos, a menudo como estrategia de respuesta a los partidos populistas (Olivas Osuna y Rama 2021).

\footnotetext{
${ }^{5}$ Vox no fue incluido en la Populism and Political Parties Expert Survey 2018, dado que en aquel momento no tenía representación parlamentaria.
}

Araucaria. Revista Iberoamericana de Filosofia, Política, Humanidades y Relaciones Internacionales, año $23, \mathrm{n}^{\circ} 47$. Segundo cuatrimestre de 2021. Pp. 371-401. ISSN 1575-6823 e-ISSN 2340-2199 https://dx.doi.org/10.12795/araucaria.2021.i47.17 
Gráfico 2: Nivel de retórica populista partidos españoles ${ }^{6}$, Global Party Survey, 2019

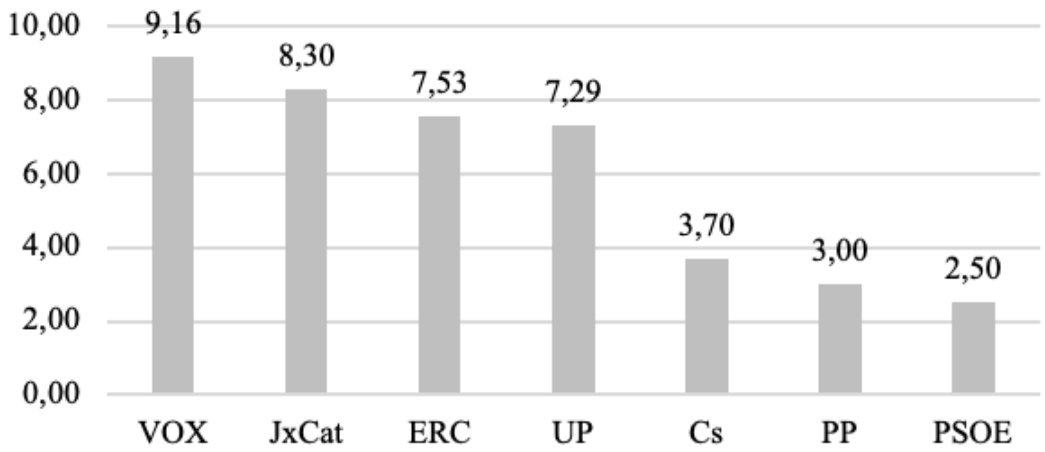

Fuente: Norris (2020)

Gráfico 3: Índice de populismo de Populism and Political Parties Expert Survey 2018

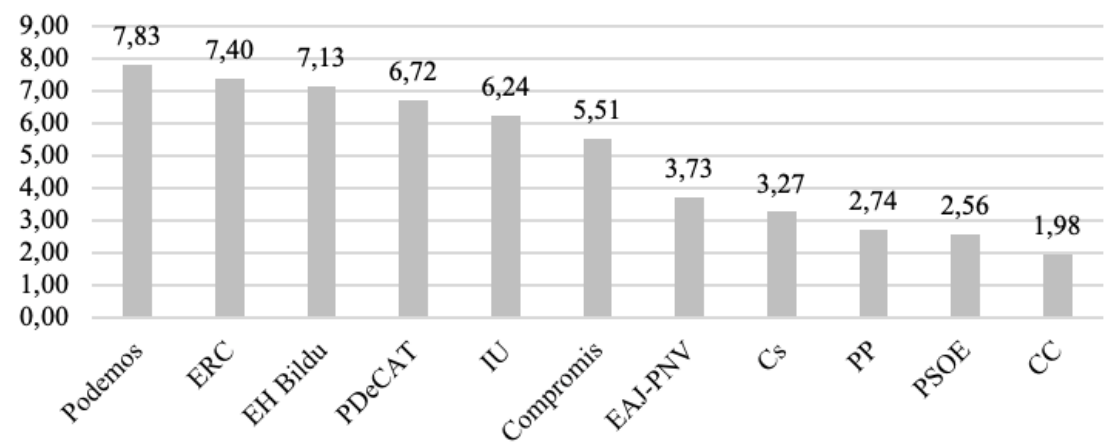

Fuente: Meijers y Zaslove (2020)

\section{Conceptualizaciones y escuelas en el estudio del populismo}

El populismo es un concepto complejo y en torno a su definición y aplicación ha habido siempre significativos desacuerdos. Ya en la mencionada conferencia pionera organizada en LSE, los participantes mostraron divergencias ontológicas en cuanto a lo que consideraban populismo y la mejor forma de analizarlo (Berlin 1968). Este término ha sufrido lo que se denomina

\footnotetext{
${ }^{6}$ Los datos de este gráfico corresponden a la Variable 9 (Populist Rhetoric) del estudio Global Party Survey.

Araucaria. Revista Iberoamericana de Filosofía, Política, Humanidades y Relaciones Internacionales, año $23, \mathrm{n}^{\circ} 47$. Segundo cuatrimestre de 2021. Pp. 371-401. ISSN 1575-6823 e-ISSN 2340-2199 https://dx.doi.org/10.12795/araucaria.2021.i47.17
} 
"estiramiento conceptual" (Sartori 1970), hasta el punto de que incluso se ha definido como "una etiqueta suelta que cubre un grupo diverso de movimientos" (Rodrik 2018: 12) y asociado a "más realidades sociales y políticas que un único término normalmente concentraría desde el punto de vista semántico" (Tăranu 2012: 131). Por ejemplo, el populismo se ha descrito como un "modo flexible de persuasión" (Kazin 1998), un "peculiar negativismo" dirigido contra las élites o minorías (Berlin 1968: 169, Canovan 1981: 294), y se ha asociado a crisis de representación (Laclau 2005a; Roberts 2019) y a una concepción iliberal de la democracia (Müller 2014; Pappas 2019).

En la esfera pública, el término populismo es usado por políticos y periodistas normalmente con un sentido peyorativo para descalificar partidos y líderes o incluso para describir al fascismo (Griffin 1991: 26). Esto dificulta aún más su estudio, puesto que raramente los individuos o movimientos se adhieren voluntariamente a esta clasificación, y este estatus analítico tiene que ser atribuido externamente (Freeden 2017: 9). Además, otro de los problemas ha sido la confusión entre populismo y nacionalismo (Brubaker 2020: 44-45; Olivas Osuna 2021: 2-3). Aunque existen diferencias en ellos, estos fenómenos se solapan y a menudo se manifiestan en conjunción, como en el caso de Vox y partidos secesionistas.

En ciencias políticas y sociología se pueden distinguir a grandes rasgos cuatro tradiciones en el estudio del populismo: (i) el enfoque ideacional que considera el populismo como una ideología "delgada" (Mudde 2004; Stanley 2008); (ii) el político-estratégico que se centra en las acciones del líder político que persigue el poder o lo ejerce (Weyland 2001); (iii) el discursivo que atribuye más peso al modo en que se articulan las demandas y afirmaciones populistas que a quien las emite (Deegan-Krause y Haughton 2009) y (iv) el performativo que incluye una dimensión sociocultural y enfatiza el estilo político del populismo (Moffitt y Tormey 2014).

Una de las definiciones más influyentes la debemos a Cas Mudde, quien afirma que el populismo es una ideología delgada (thin-centered) que considera a la sociedad separada entre dos grupos homogéneos y antagónicos -el "pueblo puro" contra la "élite corrupta"-, y que defiende la expresión directa de la voluntad popular (volonté générale) (Mudde 2004: 543). A diferencia de las ideologías "gruesas" o plenas, el populismo no aportaría una visión completa de cómo resolver los problemas políticos, sociales y económicos. Las creencias y actitudes que forman su núcleo ideológico no estarían completamente desarrollados o definidos y por ello necesita combinarse a otras ideologías clásicas, como por ejemplo el nacionalismo o el socialismo. Esta tendencia a fusionarse con otras cosmovisiones contribuye a explicar la gran variedad de populismos que se pueden encontrar en la actualidad (Ivaldi et al. 2017). 
Por otra parte, el enfoque político-estratégico inspirado en los principios de agencia y racionalidad limitada (bounded rationality)(Simon 1972) da primacía al oportunismo y a la figura del líder capaz de adaptarse a contextos específicos. Así, Weyland define populismo como "una estrategia política a través de la cual el líder busca o ejercita el poder gubernamental a través del apoyo desinstitucionalizado o directo de un gran número de seguidores, en su mayoría desorganizados" (Weyland 2001: 14). Este enfoque ayuda a explicar cómo los populistas aprovechan las crisis para reforzar su poder (Roberts 2015), así como el rápido crecimiento y/o caída de ciertos populismos debido a las acciones de sus líderes (Weyland 2020).

La aproximación discursiva defiende que el populismo es una lógica de articulación de la política $\mathrm{y}$, por lo tanto, invita a centrar los análisis en la forma en que se comunican los contenidos (Laclau 2005b: 44). Para Laclau los discursos populistas son aquellos que tratan de construir un determinado significado del "pueblo" basado en la dicotomización del espacio social a través de una frontera interna que lo separa de un "otro". Este discurso se apoya en el establecimiento de "cadenas de equivalencias" de demandas que contribuyen a homogeneizar un grupo heterogéneo de individuos, generando una nueva identidad política común basada en el antagonismo hacia dicho "otro" (Laclau 2005a; Laclau 2005b: 38; Howarth y Stavrakakis 2002: 3-4). El discurso populista busca así construir "el pueblo" como la unión de los que se oponen a un "otro" social (normalmente, las élites, inmigrantes o minorías) y luchan contra formas diferentes, pero equivalentes, de subordinación o explotación (Laclau y Mouffe 2001: xviii-xix; Laclau 2005b: 40-44).

Por último, los proponentes del enfoque performativo subrayan la importancia del componente afectivo y relacional entre el líder y el pueblo, así como entre ellos y el "otro". Además, como Laclau, asocian el populismo con la creación de clivajes e identidades, aunque en este caso enfatizan que los relatos populistas no se construyen en el vacío, sino que están influidos por las experiencias sociales y culturales previas y el contexto específico donde ocurren (Ostiguy y Moffitt 2021: 52-53). El populismo sería un estilo político basado en la afirmación y escenificación del antagonismo pueblo-élite, el uso de "malos modos", la espectacularización de las crisis y la autopresentación del líder populista como outsider, esto es, un salvador que se jacta de usar un estilo soez y agresivo (Ostiguy 2017, Moffit 2016: 45).

A pesar de las discrepancias teóricas entre las distintas tradiciones la mayoría de ellas lo conciben como una construcción social (Kim 2021) y existe un alto grado de compatibilidad y complementariedad entre ellas (Olivas Osuna 2021). Por ejemplo, incluso los defensores del enfoque ideacional argumentan que desde el punto de vista práctico las diferencias entre "ideología delgada" y "discurso" son menores (Mudde y Rovira-Kaltwasser 2018: 1669) y aconsejan 
estudiar los discursos puesto que los consideran como reflejo de la ideología subyacente (Hawkins y Rovira-Kaltwasser 2017: 514). Igualmente, tanto el enfoque estratégico-político como el performativo destacan la importancia del contexto y de las crisis. Estas no solo se asocian al origen de muchos populismos, sino que además son en parte dramatizadas, reconstruidas y propagadas por los líderes populistas para generar y aprovechar descontento ciudadano con las élites (Moffitt 2015).

En definitiva, la mayoría de los autores reconoce la existencia de un núcleo de atributos comunes a la mayoría de los movimientos populistas -tales como la interpretación maniquea de la sociedad, el anti-elitismo, la mitificación del pueblo y condena moral de los adversarios políticos-, que se manifiesta a través de los discursos y actuaciones de los líderes populistas (Moffitt 2016: 26). Se puede argumentar que los esfuerzos analíticos de estas escuelas son en gran medida sinérgicos y que cada una opera en un diferente nivel en la escala de abstracción (Sartori 1970; Olivas Osuna 2021).

\section{Deconstrucción de los relatos populistas en España}

Una forma de estudiar el populismo es deconstruyendo este fenómeno en sus componentes básicos y analizando cómo se reflejan en los discursos y actuaciones de los partidos populistas. En este artículo se utilizan como marco comparativo cinco dimensiones que sintetizan los atributos comúnmente expuestos en las conceptualizaciones más influyentes del término: i) antagonismo, ii) moralidad, iii) construcción idealizada de la sociedad, iv) exaltación de la soberanía popular, y v) liderazgo personalista (Olivas Osuna 2021). Es importante señalar que este artículo no prescribe ninguna de ellas como condición necesaria o suficiente, como sugieren muchos autores que basan su trabajo en una categorización clásica y en el uso de una "definición mínima" del populismo (Mudde 2004). Esto se debe a que, en realidad no hay un acuerdo académico en torno a cúales deben ser estos requisitos, y a que las definiciones mínimas propuestas en la actualidad suelen tener un sesgo geográfico o ideológico que limita su aplicabilidad (De la Torre y Mazzoleni 2019). Tampoco forma parte del objetivo de este estudio el clasificar como "populista" o "no populista" a los diferentes partidos políticos, ni definir su grado total de populismo, puesto que sería extremadamente difícil decidir los umbrales y criterios de peso de cada dimensión. Por lo tanto, se han seleccionado los casos de Podemos, Vox y los partidos secesionistas en base a clasificaciones previas (Norris 2020; Meijers y Zaslove 2020). Por último, aclarar que este artículo asume que el populismo es un constructo latente y que las dimensiones descritas en los párrafos siguientes se solapan e interaccionan entre ellas. 


\section{Antagonismo}

Uno de los rasgos del populismo más ampliamente aceptado es la representación maniquea de la sociedad como un enfrentamiento entre el "pueblo" contra un "otro", generalmente, las élites (Laclau 2005b: 39). Los políticos populistas suelen convertir al rival político en enemigo del pueblo (Panizza 2005) y buscan aunar y movilizar una base electoral sólida instrumentalizando el malestar ciudadano. El populismo se caracteriza por ser una suerte de reacción negativa, principalmente anti-élite o anti-establishment, pero a veces también anti-capitalista, anti-intelectual, anti-inmigración o antisemita (Berlin 1968: 168-169). Mientras el antagonismo nacionalista parte de una concepción horizontal o territorial de la distinción intergrupal, los populistas substituyen o añaden a esta una distinción jerárquica o vertical: los de abajo contra los de arriba (De Cleen y Stavrakakis 2017: 309-312). Estos antagonismos verticales y horizontales aparecen a menudo entrelazados y dirigidos a unos "otros" tan diversos como la Unión Europea (UE), el imperialismo americano, el capital global, los refugiados o las amenazas culturales que vienen de fuera (Brubaker 2020: 54-58).

Podemos basó su estrategia de comunicación inicial en denunciar los abusos de "la casta", refiriéndose a una élite extractora que había arruinado al pueblo y en calificar al PP y PSOE como "partidos de la casta" (Ramiro y Gómez 2016). Podemos reclamaba "poner fin al robo sistemático de dinero público que unas élites políticas corruptas han llevado a cabo durante décadas con total impunidad" (Podemos 2016: 188). Por su parte Vox, aunque también ha criticado a los dos grandes partidos, dirige su antagonismo fundamentalmente contra los inmigrantes, para quienes solicita leyes más restrictivas (Vox 2019a: 10-13; Vox 2019b:5-6; Turnbull-Dugarte 2019), y contra los independentistas catalanes y vascos, que adquieren el papel de "enemigo interior" y son acusados de "atentar contra el orden constitucional y la unidad de la Nación Española" (Vox 2019a: 8; Vampa 2020). Mientras tanto, el proceso de otredad ("othering") por parte de los partidos secesionistas catalanes señala al "estado español", a quien consideran "hostil" y "desleal", y que coarta la libertad y progreso del pueblo catalán (Junts Pel Sí 2015: 10-16). Igualmente, Otegui, el líder de EH Bildu, declaraba en una entrevista en la televisión pública vasca: "El Estado español no tiene ningún mecanismo para evolucionar hacia un modelo que respete los derechos nacionales y sociales"'.

El antagonismo populista a menudo se refleja en el empleo de una retórica hiperbólica y simplista contra el "otro", así como en el uso de términos militaristas en las descripciones de las dinámicas políticas (Taguieff 1984: 125126): idealización y estetización de la batalla o la confrontación (Krasteva y

\footnotetext{
${ }^{7}$ Teleberri “Arnaldo Otegi, en ETB: la entrevista íntegra”, 4 marzo 2016.
} 
Lazaridis 2016: 18-20). Esta retórica puede considerarse parte de la estrategia performativa a través de la cual los populistas tratan de aumentar y perpetuar la sensación de crisis y confrontación (Moffitt 2015). El uso de malos modos y agresividad de una forma desinhibida forma parte además del estilo habitual de populistas (Ostiguy 2009; Moffitt 2016).

Estos rasgos son observables en los discursos de los partidos populistas españoles. Por ejemplo, Pablo Iglesias inauguraba la asamblea fundacional de Podemos en 2014 con el lema "El cielo no se toma por consenso, se toma por asalto" y recientemente anunciaba su candidatura a la presidencia de la Comunidad de Madrid llamando a "hacer frente a esa derecha criminal", explicando que "en política hay que tener valentía, valentía para dar las batallas que hay que dar" y que "el 4 de mayo se decide si la ultraderecha consuma su asalto a Madrid o si les paramos". Por su parte Vox ha hecho frecuente uso de referencias a la Reconquista. La cuenta oficial de Twitter del partido pedía: "Volver a los principios con Vox: \#EspírituDeCovadonga" (1 diciembre 2015) y "No queremos, ni debemos olvidar, que hoy hace 527 años de la liberación de Granada por las tropas españolas de los Reyes Católicos, poniendo fin a ocho largos de siglos de Reconquista contra el invasor musulmán" (2 enero 2019). Abascal, además, declara la "guerra política" a un Gobierno del "Frente Popular”, en alusión al último gobierno de la Segunda República, que fue derrotado en la Guerra Civil ${ }^{10}$.

Mientras tanto el independentismo también ha utilizado un relato de confrontación. Por ejemplo, ERC en su programa electoral autonómico de 2017 mencionaba 15 veces la palabra "represión" y usaba otros términos como "ofensiva", “intimidación”, “amenaza” y "agresión” para describir una supuesta campaña del Gobierno de España contra Cataluña (ERC 2017: 4-9). Además, los grupos secesionistas han justificado la violencia como medio para visibilizar el conflicto en Cataluña ${ }^{11}$, invitado a los grupos más radicales a hacer presión $^{12}$ y mitificado algunas acciones violentas como la llamada "batalla de Urquinaona"13. Parte de este relato es también la calificación de los cuerpos de Policía Nacional y Guardia Civil como "fuerzas de ocupación"14. En el caso vasco, a pesar de oficialmente haber dejado de apoyar la lucha armada, es

${ }^{8}$ ElDiario.es, "Pablo Iglesias abre la Asamblea de Podemos: 'El cielo no se toma por consenso: se toma por asalto", 18 octubre 2014.

9 El País, "El mensaje completo de Pablo Iglesias en el que anuncia que deja el Gobierno", 15 marzo 2021.

${ }^{10}$ VozPópuli, Abascal declara la "guerra política" a un Gobierno del "Frente Popular", 11 diciembre 2019.

11 SER, "El independentismo justifica la violencia en Cataluña", 28 octubre 2019; VozPopuli, "El 96\% de la violencia política en Cataluña es obra del independentismo", 7 mayo 2020.

12 RAC1, “Quim Torra, als CDRs: 'Apreteu i feu bé d'apretar”, 1 octubre 2018.

${ }^{13}$ Referencia a los enfrentamientos violentos entre manifestantes independentistas y la policía en la Plaza Urquinanoa de Barcelona. Vilaweb, “18 d'octubre, la batalla d'Urquinaona”, 18 octubre 2020.

14 El País, “¡Fuera las fuerzas de ocupación!”, 4 octubre 2017. 
notorio como líderes y militantes de EH Bildu han participado y justificado los "ongi etorri", homenajes a terroristas de ETA excarcelados ${ }^{15}$.

Otro aspecto de esta dimensión que cabe destacar es que el populismo suele construirse como una empresa "contra-hegemónica" y contra el status quo (Panizza 2005: 3-4; Errejón y Mouffe 2015), cuyo impulso procede en buena medida de la indignación y la frustración de los ciudadanos (Müller 2016: 9, 15-17). De ahí que el populismo suela defender la necesidad de llevar a cabo un cambio radical del sistema político y de sus instituciones, que se han degradado en manos del establishment. Los populistas se alimentan de crisis económicas, sociales y políticas, reales o percibidas, e intentan reinterpretarlas y propagarlas para justificar cambios drásticos en el sistema institucional (Moffitt 2016: 45).

En el caso español este atributo se hace más que evidente. Podemos inició su andadura prometiendo acabar con el "régimen del 78", en referencia al sistema institucional desarrollado a partir de la Constitución Española durante la Transición ${ }^{16}$. Este partido también adoptó una postura euroescéptica como reacción a las políticas de austeridad propugnadas por la UE tras la Gran Recesión (Gómez-Reino y Plaza-Colodro 2018). Aunque su discurso ha sufrido cambios significativos a partir de 2015 y Podemos ha matizado su postura hacia la Transición (Franzé 2017), en la actualidad, a pesar de formar parte de la coalición de gobierno, este partido aún escenifica frecuentemente su antagonismo hacia instituciones tales como la Monarquía, la Justicia ${ }^{17}$, las Fuerzas Armadas, la Policía ${ }^{18}$ y la prensa. ${ }^{19}$

Vox se presenta como fuerza defensora de la Constitución y la Monarquía, pero también propone transformaciones radicales y critica muchas instituciones españolas y de la UE. Por ejemplo, Vox propugna que se eliminen cargos y organismos que ellos consideran "ideológicos" o "prescindibles", la supresión de televisiones públicas, la fusión de ayuntamientos, así como la transformación de España en un estado unitario sin gobiernos ni parlamentos regionales (Vox 2019b: 3, 9). También proponen eliminar agencias europeas que "se inmiscuyan en la soberanía nacional" y toda la representación política exterior de regiones y municipios (Vox 2019a: 10).

Por su parte, los partidos independentistas reivindican la secesión y creación de un nuevo estado y marco legal. Estos partidos, aunque antagonizan y desafían a las instituciones españolas como la Casa Real, tribunales, policías

${ }^{15}$ El Correo, "Bildu se queda solo con los 'ongi etorris", 25 junio 2020,

${ }^{16}$ El País “Pablo Iglesias promete acabar con el 'régimen' de la Transición”, 16 noviembre 2014.

17 ABC, "Las críticas de Podemos a la Justicia y la Monarquía erosionan la coalición: 'No están cumpliendo", 17 diciembre 2021.

${ }^{18}$ El Mundo, "Policías y militares acusan a Pablo Iglesias de 'falta de respeto intolerable' por ver prescindible su labor en la lucha contra el coronavirus", 23 septiembre 2020,

19 Asociación de Prensa de Madrid, "Comunicado ante el acoso de Podemos a periodistas", 6 marzo 2017. 
y Fuerzas Armadas ${ }^{20}$, suelen defender y elogiar a las instituciones autonómicas. Son habituales las llamadas a la desobediencia y a disputar el control del territorio al Estado ${ }^{21}$. También las escenificaciones de rechazo a las instituciones con actos como la quema de constituciones o de fotos del Rey, los silbidos al himno de España en competiciones deportivas o los ataques a las sedes de los partidos políticos de ámbito nacional ${ }^{22}$. Al igual que Podemos, los partidos independentistas aluden a menudo a "las cloacas del Estado" en referencia a métodos de guerra sucia y corrupción en los que presuntamente hay envueltos políticos y funcionarios (Junts per Catalunya 2019:10) ${ }^{23}$. Tras el rechazo de Bruselas a la declaración unilateral de independencia de Cataluña en 2017, el independentismo que tradicionalmente fue eurófilo ha comenzado a criticar a la UE en su discurso (Portos 2020).

\section{Moralidad}

Otra característica de los discursos populistas es el establecimiento de una jerarquía moral entre los diferentes actores políticos. El populismo no solo enfrenta al "pueblo" con el "otro", sino que esta distinción, más que empírica, es moral (Mudde 2004:543, Laclau 2005b: 4). Se busca provocar emociones negativas como la indignación, enfado, miedo y odio que contribuyen a justificar la exclusión del "otro" y movilizar al electorado (Moffitt 2015; Wodak 2015; Rico et al. 2017). Los populistas a menudo expresan la necesidad de una regeneración moral (Berlin 1968: 174) y se consideran los únicos defensores del bien común y del "pueblo" (Müller 2016: 3). Esta dimensión moral se refleja asimismo en el empleo de un discurso de culpabilización del "otro" (Vasilopoulou et al. 2014) y la victimización del pueblo (Homolar y Löfflmann 2021).

Los populistas suelen anteponer la rectitud y virtud a la eficacia y utilidad, ya que su concepción de la política es más moralista que programática (Wiles 1969: 167). Usando la terminología aristotélica cabe afirmar que los líderes populistas, en lugar de centrarse en el logos -datos, hechos y argumentación

${ }^{20}$ El Periódico "Otegi acusa al Supremo de "desestabilizar el escenario político", 15 diciembre 2020; El País, "Los manifestantes contra el Rey impiden la entrada de invitados con abucheos y empujones", 4 noviembre 2019. 2021 ,

${ }^{21}$ ARA, "Ex dirigentes de Tsunami preparan acciones inminentes para reactivar la calle", 27 abril

${ }^{22}$ La Vanguardia, "La periodista Empar Moliner quema en directo la Constitución Española en TV3", 12 abril 2016; ElDiario.es "La presidenta de la ANC quema una foto gigante del rey Felipe VI en las protestas en Barcelona", 9 octubre 2020; El Diario Vasco, "Los ataques a sedes a partidos políticos en Euskadi se elevan a 36 dentro de la campaña de acoso por disidentes de la izquierda abertzale", 26 mayo 2020,; La Vanguardia, "El PSC sufre el 60\% de los ataques contra sedes de partidos en Catalunya", 13 de febrero 2020.

23 Podemos, "Iglesias: 'Proponemos combatir las cloacas del estado con la constitución en la mano",, 9 abril 2019. 
racional-, utilizan su ethos -credibilidad, reputación y atractivo ético- y el pathos -atractivo emocional- para persuadir a la ciudadanía de sus propuestas políticas. Además, reclaman tener superioridad moral sobre sus adversarios políticos, a los que intentan ridiculizar y deslegitimar, a menudo aludiendo a motivos ocultos y malas intenciones (Taguieff 1984: 118).

En España el crecimiento del populismo ha venido acompañado también con una moralización del debate político. En el caso de Podemos son constantes las alusiones a la corrupción de los políticos, altos cargos de la administración, empresarios y periodistas ${ }^{24}$. Una vez integrado en la clase política, Podemos substituye "la casta" por el concepto de "la trama", en referencia a una supuesta red de corrupción dirigida por ciertas élites ${ }^{25}$. En la misma línea este partido ha llegado calificar como "ilegítimas" a instituciones como el Gobierno de Mariano Rajoy o el Consejo General del Poder Judicial ${ }^{26}$. Sus líderes frecuentemente tratan de desacreditar a los partidos de centro-derecha y derecha llamándolos "criminales", "fascistas" o asociándolos con el franquismo" 27 . Iglesias incluso llega a afirmar que a Vox le "gustaría dar un golpe de estado", pero no se atreven $^{28}$.

Vox utiliza un lenguaje hiperbólico para descalificar moralmente a políticos, periodistas, instituciones y grupos sociales a los que se opone. Por ejemplo, durante el debate parlamentario sobre el estado de alarma por la pandemia de COVID-19, Abascal acusaba al Gobierno de comportarse "como una mafia", "negligencia criminal" y "sectarismo". En esa misma sesión parlamentaria declaraba: "Yo creo que el señor Iglesias desea una guerra civil, pero yo no voy a decir que no se atreve, porque creo que, en su vanidad y en su fanatismo, es capaz de provocar cualquier drama en España" y acusaba al diario El País de blanquear los crímenes del terrorismo ${ }^{29}$. Vox además acusa a los independentistas de golpismo, a los inmigrantes de abusar de los servicios públicos y del aumento de la criminalidad, y a la izquierda de fomentar la violencia, cometer "fraude electoral" y tener una "ideología totalitaria ${ }^{30}$. Al igual que otras formaciones de derecha radical, Vox se presenta como víctima de

\footnotetext{
${ }^{24}$ El Mundo, "Podemos exhibe un autobús contra políticos, periodistas y empresarios", 17 abril 2017.

25 El País, "Podemos reemplaza la 'casta' por la 'trama'”, 13 marzo 2017.

${ }^{26}$ El Correo, “Iglesias apoya la marcha contra el 'Gobierno ilegítimo’ de Rajoy”, 25 octubre 2016; ElDiario.es, "Unidas Podemos rechaza el comunicado 'ilegítimo’ del CGPJ contra Iglesias y dice que está 'al servicio de la derecha”, 23 abril 2020.

${ }^{27}$ El Español, "Iglesias llama 'fascista' a Rivera y alecciona a Sánchez sobre cómo ser presidente", 31 mayo 2018; El País, "El mensaje completo de Pablo Iglesias en el que anuncia que deja el Gobierno", 15 marzo 2021; Europa Press, "Iglesias responde a Aguirre que el aliado de Goebbels fue Franco, el "padre político del PP"', 16 de julio 2014

28 El País, "Iglesias, a VOX: Les gustaría dar un golpe de estado", 28 mayo 2020.

${ }^{29}$ Congreso de los Diputados, "Diario de Sesiones", 3 junio 2020.

${ }^{30}$ Vox, "VOX publica la lista de agresiones sexuales que el Gobierno oculta", 3 marzo 2020 ; El Matinal, "Rocío Monasterio no quiere que los españoles paguen la sanidad a los inmigrantes ilegales: 'Es un insulto"” 14 junio 2019; Vox, "La izquierda es violencia", 28 abril 2021.
} 
la exclusión y ataques de otros partido ${ }^{31} \mathrm{y}$ promueve teorías de la conspiración contra el Gobierno, George Soros, China o la Organización Mundial de la Salud (Olivas Osuna y Rama 2021).

La superioridad moral y el victimismo son también elementos centrales en el populismo de los partidos independentistas, quienes describen su lucha por la independencia como una lucha entre un virtuoso y pacífico movimiento democrático contra un estado autoritario y represor ${ }^{32}$. Incluso actos considerados ilegales por tribunales de justicia son justificados como acciones "democráticas" 33 . Estos partidos acusan a instituciones como el Gobierno y el Tribunal Constitucional de querer "humillar a Cataluña" (Junts pel Sí 2015: 27) y sostienen que España vive subsidiada por ésta (ERC 2017: 13), o incluso que directamente "roba" a Cataluña (Moreno-Almendral 2018: 133). Las críticas no se refieren solo a hechos concretos, sino que caracterizan como inmanentes estos rasgos negativos. Por ejemplo, se habla de "instinto represivo del Estado español"34, y se califica a éste como "postfranquista" (CUP 2015: 44) o "fascista" 35 . Dirigentes de JxCat han llegado a afirmar que "España trata a Cataluña como a una colonia" y que "España es paro y muerte" mientras Cataluña es "vida y futuro" 36 . Finalmente, también se puede destacar cómo estos partidos usan teorías de la conspiración para deslegitimar al Estado, por ejemplo, en el caso de los ataques terroristas en Cataluña en 2017 o durante la pandemia de COVID-1937.

\section{Idealización de la sociedad}

Otro de los rasgos típicos del populismo es la idea romantizada y antipluralista de "pueblo", destacando la homogeneidad dentro de este y la diferencia con el "otro". Los populistas reconstruyen discursivamente una patria o heartland basándose en una concepción ahistórica y emocional del

${ }^{31}$ ABC, "Abascal se aferra al victimismo mientras crece el descontento con su núcleo duro", 23 octubre 2020.

32 Òmnium Cultural, "Help Catalonia. Save Europe”, 16 octubre 2017, Público, “Arnaldo Otegi: 'El problema ya no es independencia o no, sino autoritarismo o democracia'”, 3 octubre 2019; El Periódico, "Puigdemont acusa a un 'Estado autoritario' de prohibir que debatan los cabezas de lista", 14 mayo 2019,

33 Por ejemplo, la organización de un referéndum ilegal de independencia en 2017 con la campaña de comunicación "Love Democracy" (Olivas Osuna 2017) y las acciones de la y Tsunami Democràtic. El Mundo, "Qué es Tsunami Democràtic: manual para la rebelión independentista en tiempos de WhatsApp", 16 octubre 2019.

${ }^{34}$ El Periódico, "That's all folks", 30 septiembre 2017.

35 Vozpópuli, "La nueva voz de Junts en el Congreso buscará dinamitar los puentes entre Sánchez y ERC", 25 febrero 2021. 2021 ,

${ }^{36}$ Crónica Global, "Hispanofobia y polémicas de los diputados de Junts per Catalunya", 15 febrero

${ }^{37}$ El Independiente, "El independentismo resucita la teoría de la conspiración por los atentados de Barcelona", 27 julio 2017; ABC, "Pilar Rahola: 'Ya lo tenemos, un 155 encubierto con la excusa del coronavirus",, 16 marzo 2020. 
pasado (Taggart 2000: 3-5). De ahí que Mudde (2004: 546) compare la patria o heartland populista con la "comunidad imaginada" de Benedict Anderson (1983). Los populistas reinterpretan el pasado de una forma selectiva con el objetivo de generar nuevos recuerdos colectivos. Esta reelaboración de la historia se usa para destacar relatos victimistas y de culpabilización, para resaltar aspectos heroicos y para cancelar hechos inconvenientes (Caramani y Manucci 2019: 1163-1165). Los relatos de humillación y las reinterpretaciones de triunfos y traumas históricos ayudan a crear un vuelco emocional en el electorado y alejarlo del racionalismo en la toma de decisiones y del voto a los partidos tradicionales. Al mismo tiempo, estos relatos se usan para acercarse a las políticas basadas en emociones y a los partidos que fomentan sentimientos de indignación (Homolar y Löfflmann 2021: 8-9).

La exclusión y homogeneización también son clave en la interpretación populista de la sociedad (Jagers y Walgrave 2007: 323). Los populistas emplean fronteras interiores y "significantes vacíos", es decir, símbolos o conceptualizaciones de ideales universales poco definidos y maleables, que cumplen una función homogeneizadora en el marco de una realidad altamente heterogénea (Laclau 2005b: 39-40). Estos sirven para aglutinar a personas y grupos haciéndoles sentir como equivalentes en sus diversos miedos, quejas o resentimientos contra el "otro". Para que el pueblo se ajuste a su versión idealizada, los populistas suelen exigir la creación de fronteras internas y la expulsión de una parte de ciudadanos de este "pueblo" (Müller 2014). Las élites corruptas, los inmigrantes o los colonizadores, no deben ser considerados parte del "heartland" ni del demos, y se invita al pueblo "auténtico" a luchar contra estos outsiders para alcanzar la plenitud y "retomar el control" de su país (Panizza 2005: 3-4). La deshumanización del enemigo se convierte en herramienta para justificar exclusión (Arato 2013: 167). Igualmente, el reforzamiento de fronteras existentes o la creación de nuevas, ya sean políticas, económicas o culturales, se convierte en elemento clave en la redefinición del pueblo (Olivas Osuna 2020).

Como parte de la creación de una nueva identidad política, Podemos promueve una revisión histórica, en particular de la Guerra Civil y de la Transición. La primera sirve para asentar el relato maniqueo de la sociedad española que estaría dividida aún entre los bandos de dicho enfrentamiento: la "democrática y anti-fascista izquierda" contra la "anti-democrática y fascista derecha"38. Mientras tanto la Transición es reinterpretada como frustración histórica, dirigida por las élites y condicionada por el franquismo (Rueda Laffond 2016: 745), lo que serviría para abandonar la idea de que esta fue resultado de un consenso social y así justificar la necesidad imperiosa de una segunda Transición. Además, Podemos busca una nueva interpretación

38 El País, "La izquierda reinventa la campaña: 'Ya va de democracia o fascismo"”, 25 abril 2021. 
hegemónica de la sociedad como parte del proceso de construcción de un "pueblo nuevo" (Franzé 2017: 237-240). Aunque este partido es claro defensor de la inmigración, diversidad y multiculturalidad, su concepción de España como un Estado compuesto por cuatro naciones, la española, la vasca, la gallega y la catalana ${ }^{39}$, es reduccionista y cuestionable a nivel teórico y empírico, ya que disocia la identidad española de la de estas tres regiones y omite las divergencias identitarias en el resto de las autonomías (Fernández-Albertos y Lago 2015). Líderes de este partido también han justificado "escraches" y performances que deshumanizan o humillan a rivales políticos ${ }^{40}$.

Vox instrumentaliza la historia de España rechazando Al-Andalus y reivindicando la Reconquista como mito fundacional (García Sanjuán 2020). Defiende una concepción tradicionalista cristiana de la sociedad española, con tintes nativistas, y con alusiones a la exclusión de ciertos grupos e instituciones. Por ejemplo, Vox propone el "cierre de mezquitas fundamentalistas, y expulsión de los imanes que propaguen el integrismo", "exclusión de la enseñanza del Islam de la escuela pública" y "creación de una agencia para la ayuda a las minorías cristianas amenazadas" (Vox 2019b: 7, 23). Un eje importante del discurso de Vox es oponerse a lo que llaman "ideología de género" y al feminismo ${ }^{41}$. Pide la supresión de "organismos feministas radicales subvencionados" y se opone al matrimonio entre personas del mismo sexo, reclamando la protección de la "familia natural" (Vox 2019b: 17). En línea con otros partidos de derecha radical, Vox ha adoptado un discurso anti-inmigración proponiendo la "deportación de los inmigrantes ilegales a sus países de origen", nuevos requisitos y barreras para la nacionalidad y el establecimiento de cuotas en base a criterios lingüísticos y culturales (Vox 2019a: 10-13, Vox 2019b: 5-6). Reclama hacer un "frente común contra la invasión cultural extranjera" en Europa, sugiriendo dificultar la inmigración de África y Oriente Medio, y rechazando la entrada de Turquía en la UE (Vox 2019a: 9). Vox utiliza un discurso que criminaliza a los inmigrantes indocumentados, incluyendo a los menores extranjeros no acompañados (MENAs), a los que identifica como criminales ${ }^{42}$.

Esta dimensión del populismo es aún más visible en los independentismos vasco y catalán, los cuales recurren constantemente a la revisión histórica y a una concepción etnolingüística de la sociedad. Construyen mitos históricos

${ }^{39}$ Público, "Pablo Iglesias: 'En España hay cuatro naciones que comparten un mismo Estado"”, 15 noviembre 2017.

${ }^{40} \mathrm{ABC}$, "Podemos de Jerez limpia con lejía la calle donde Vox repartió propaganda", 21 marzo 2019; El Español, "Podemos justifica los ataques contra Cs en el Orgullo por 'ir de la mano de Vox", 30 junio 2019; La Voz de Galicia, "Iglesias vuelve a defender el «jarabe democrático» de los escraches contra el PP", 30 diciembre 2020.

${ }^{41}$ Vox, "Ideología de género", 2021.

${ }^{42}$ El Mundo, "La Fiscalía investiga por un posible delito de odio el cartel electoral de Vox contra los menores inmigrantes", 21 abril 2021.

Araucaria. Revista Iberoamericana de Filosofia, Política, Humanidades y Relaciones Internacionales, año $23, \mathrm{n}^{\circ} 47$. Segundo cuatrimestre de 2021. Pp. 371-401. ISSN 1575-6823 e-ISSN 2340-2199 https://dx.doi.org/10.12795/araucaria.2021.i47.17 
gracias a una reinterpretación selectiva de periodos y acontecimientos. Ambos movimientos recrean un pasado separado o enfrentado al resto de España, donde se refleja una ambición irredentista en la construcción de un estado que aglutine todos los territorios donde se habla el euskera y el catalán, los imaginarios "Euskal Herria" y "Països Catalans" que incorporarían otras Comunidades Autónomas españolas y áreas de Francia e Italia (Mansvelt Beck 2006; UcelayDa Cal 2013). Los populistas consideran que la única "lengua propia" o "de país" en estas Comunidades es el euskera y el catalán respectivamente y, en consecuencia, intentan reducir o excluir el uso del español en la esfera pública a pesar de que ésta es la lengua de uso preferente de una mayoría de vascos y catalanes. Estos partidos enfatizan las diferencias culturales y sociales con el resto de España y minimizan las internas. Por ejemplo, en Cataluña se eliminan personajes históricos españoles de los callejeros ${ }^{43}$ y se considera al catalán como pueblo único y singular (Junts pel Sí 2015: 98). Se hacen frecuentes alusiones a la idea de un "sol poble" (un único pueblo) y la supuesta existencia de "grandes consensos de país" (ERC 2017: 12), omitiendo el hecho de que la sociedad catalana está fragmentada socioétnicamente y polarizada políticamente (Oller et al. 2019).

Estos nacionalismos también manifiestan un cierto grado de nativismo, ya que establecen una distinción entre vascos y catalanes "auténticos" y los españoles que viven en estas Comunidades Autónomas. A estos últimos se les llega a calificar despectivamente como "inmigrantes", "maketos", "coreanos", "charnegos", "ñordos" o "colonos" (Clua i Fainé 2011; Muro 2013: 59, 100). Estos populismos asocian en ocasiones al verdadero vasco o catalán con el nacionalista vasco o catalanista, o con quien tiene ascendencia vasca o catalana. A pesar de exaltar el carácter diverso e inclusivo de estas Comunidades, son habituales los acosos, señalamientos, insultos y deshumanización de políticos, jueces, policías y periodistas, por parte de estos independentismos ${ }^{44}$. Llegándose incluso a justificar que se discrimine a los agentes de Policía Nacional y Guardia Civil en la campaña de vacunación por la pandemia de COVID-19 en Cataluña ${ }^{45}$. También utilizan frecuentemente relatos y escenificaciones victimistas, de humillación y sufrimiento (López Romo y Fernández Soldevilla 2018; Ruiz Casado 2020), exagerando agravios para justificar la independencia (Griffiths y Martinez 2020).

\footnotetext{
${ }^{43}$ ABC, "La silenciosa depuración de España en el callejero de Cataluña", 28 agosto 2017.

44 Por ejemplo; el uso de términos como "txakurra" o "botifler", La Vanguardia, "Decena de personas con trajes de fumigar limpian la calle tras pasar Rivera", 18 mayo 2019, ElPlural.com, "La otra cara del independentismo: amenazas, ataques, insultos...”, 1 mayo 2018; ElDiario.es, “¿Es racista el discurso de Quim Torra?", 28 mayo 2018.

${ }^{45}$ El Periódico, "Puigdemont carga contra la vacunación de Policía y Guardia Civil en Catalunya", 27 abril 2021.
} 


\section{Exaltación de la soberanía popular}

La exaltación del "pueblo" y de la "soberanía popular" son elementos centrales en el populismo (Canovan 1981: 294; Panizza 2005: 4-5). Los populistas entienden la democracia como el gobierno del pueblo soberano y sugieren la supremacía de este sobre cualquier institución política o legal, así como la necesidad de establecer una relación no mediada entre la gente y el gobierno (Canovan 2002: 33-37). Esta lógica emana de la interpretación antagónica, moralizante e idealizada de la sociedad. Se recela de leyes e instituciones que puedan limitar la voluntad popular, máxime si se las entiende creadas o corrompidas por la élite en la que no se confía. Los populistas son a menudo hostiles hacia el discurso de los derechos de individuos y minorías, que son subordinados a la "voluntad del pueblo", en lo que puede considerarse una concepción extrema del "mayoritarismo" (Mudde 2013: 4). Esta concepción mayoritarista de la política queda plasmada en la importancia que los populistas dan a los instrumentos de la democracia directa, como referendums, consultas públicas, iniciativas populares y movilizaciones masivas (Canovan 1981:177; Taggart 2000: 103-105).

El populismo puede ser considerado como un discurso empoderador y un correctivo para la democracia. La exaltación populista de la soberanía y las llamadas a "recuperar el control" contribuyen a acercar a los ciudadanos a los asuntos públicos y ampliar la participación política (Canovan 2002: 42-43; Vallespín y MartínezBascuñan 2017). Sin embargo, la premisa populista de que el bien común es fácilmente discernible por la gente conduce a soluciones políticas simplistas basadas en el "sentido común" y a menudo contra el criterio dominante de los expertos (Müller 2016: 25- 31). Más aún, los populistas tienen una concepción iliberal de la voluntad del pueblo, que limita el pluralismo y la deliberación y rechaza contrapesos de poder (Kriesi 2018: 8-9; Pappas 2019). Se puede interpretar que el populismo busca disociar la democracia del liberalismo imponiendo un mandato unitario y hegemónico por parte de una mayoría (Urbinati 2014).

Podemos fue creado con la intención de canalizar el impulso ciudadano de los Indignados, construir una mayoría social y una hegemonía política, para así poder recuperar la soberanía perdida a manos de organismos europeos -como la Troika comunitaria- y élites nacionales -"la casta" (Iglesias Turrión 2014; Errejón y Mouffe 2015; 2016). Este partido utiliza un discurso cívico que llama a la participación ciudadana activa y aboga por la extensión de referendums y otros instrumentos de democracia directa en los procesos decisorios (PérezNievas et al. 2018). Por ejemplo, propone en su programa electoral que cuando un $15 \%$ del censo lo solicite se convoque un referéndum vinculante para forzar nuevas elecciones generales, así como la organización de un referéndum de independencia en Sahara Occidental y Cataluña (Podemos 2019: 50, 54, 104). 
Aunque las alusiones a la soberanía son también frecuentes en el discurso de Vox, este partido adopta una concepción más tradicional de este concepto sin enfatizar el componente ciudadano o de democracia directa. Vox mantiene una posición más nacionalista que populista en lo que respecta a la necesidad de proteger la "soberanía nacional", que entiende amenazada por los movimientos secesionistas, Marruecos e instituciones europeas (Vox 2019a: 2, 4; Vox 2019b: 2, 6, 8, 21). Aunque las movilizaciones masivas son cada vez más una herramienta de presión de este partido, rara vez el partido o sus líderes se refieren a la necesidad de implicar más directamente a la ciudadanía en los procesos decisorios.

De nuevo es entre los partidos secesionistas donde la dimensión de exaltación de la soberanía tiene más peso. Son recurrentes los discursos que defienden la ausencia de límites para la voluntad popular, situando a esta por encima de leyes, tribunales y derechos individuales ${ }^{46}$. Se argumenta que existe un conflicto entre la legalidad y la legitimidad que emanaría del pueblo (Barrio et al. 2018: 1001). Además, es frecuente el uso eufemístico del término "derecho a decidir" para referirse a un supuesto derecho de secesión o de fusión de Comunidades Autónomas para crear "Euskal Herria" o los "Països Catalans" "47. En línea con otros grupos populistas, el independentismo idealiza las herramientas de democracia directa como referéndums, asambleas no representativas y movilizaciones masivas defendiendo que un mandato popular debe respetarse incluso si entra en conflicto con la ley (Ruiz Casado 2020). La lógica mayoritarista está muy presente, pero se aplica de una forma selectiva. Por ejemplo, estos partidos defienden que una mayoría simple en Cataluña sería suficiente para declarar la independencia, aunque se vulneren la Constitución Española y el Estatuto de Autonomía que fueran avalados por mayorías más amplias (Junts pel Sí 2015: 30-34; ERC 2017: 3-7).

\section{Liderazgo personalista}

Por último, la dependencia del líder carismático es también un rasgo habitual en los populismos (Taggart 2000: 100-103, Laclau 2005a), que son movimientos que suelen emerger cuando un dirigente personalista moviliza y recibe el apoyo de una masa amplia de personas (Weyland 2001: 4-18). En ocasiones incluso se denomina a éste en referencia al líder, como en el pujadismo francés, el peronismo argentino, el chavismo venezolano o el trumpismo norteamericano. En el populismo, el líder es tenido por una encarnación del pueblo, como alguien capaz de discernir y articular su voluntad, evitar que

${ }^{46}$ El Mundo, "Junqueras al jefe de seguridad atrapado en la Consellería de Economía: 'Es la voluntad del pueblo"”, 25 marzo 2019.

${ }^{47} \mathrm{ABC}$, "Bildu exige un referéndum sobre la anexión de Navarra a una 'república vasca confederal"”, 3 diciembre 2020.

Araucaria. Revista Iberoamericana de Filosofía, Política, Humanidades y Relaciones Internacionales, año $23, \mathrm{n}^{\circ} 47$. Segundo cuatrimestre de 2021. Pp. 371-401. ISSN 1575-6823 e-ISSN 2340-2199 https://dx.doi.org/10.12795/araucaria.2021.i47.17 
caiga en la desunión (Arato 2013: 156-166; Müller 2016: 32-38). Su relación con ese pueblo no tiene por qué estar mediada por partidos, parlamentos u otras instituciones. Esta conexión idealizada entre el líder populista y su pueblo está vinculada a la idea de que las instituciones y partidos han sido corrompidos.

La figura del líder facilita la identificación afectiva del ciudadano con el movimiento populista (Arias Maldonado 2017). La inmediatez en la comunicación que permiten redes sociales, unida a la carga emotiva del mensaje y a un estilo performativo desinhibido, contribuyen a consolidar esta conexión afectiva (Moffitt 2016). Sin embargo, este liderazgo directo y personalista puede acabar generando un culto a la personalidad y desembocar en un Cesarismo o Bonapartismo que erosione las instituciones (Urbinati 2014: 153).

Pablo Iglesias, inspirado por el trabajo de Laclau (2005), adoptó en Podemos el papel de líder carismático que representa la unidad necesaria para homogeneizar la enorme variedad de agravios y demandas del pueblo contra el sistema y la casta (Errejón y Mouffe 2016: 109). Iglesias se convertiría en el "significador vacío" que encarna la voluntad popular (De Nadal 2020: 47). Este liderazgo personalista generó tensiones tanto a nivel teórico como práctico dentro de Podemos, ya que la concentración de poder organizativo en manos de Iglesias contrastaba con el discurso más horizontal de participación que se comunicaba de cara al exterior (De Nadal 2020: 51). A medida que muchos de los cofundadores del partido como Juan Carlos Monedero, Luis Alegre, Carolina Bescansa o Iñigo Errejón fueron apartados o abandonaron sus cargos, este proceso de personalización se intensificó. Un ejemplo reciente de este personalismo es el anuncio sorpresa de que Iglesias dejaba la Vicepresidencia del Gobierno para presentarse como candidato a la Comunidad de Madrid, desplazando a la que había sido la anterior candidata, Isabel Serra, sin mediar proceso de primarias y donde aseguraba que "a la derecha se la frena [...] con una candidatura fuerte y con carácter"48. Iglesias aparecía muy frecuentemente en los medios de comunicación, llegando incluso a presentar un programa de TV. Es además con diferencia el líder político español más popular en Twitter con más de 2,6 millones de seguidores, su cuenta ha servido para diseminar propaganda política, demonizar a rivales políticos y ensalzar la figura de Iglesias (Bonete Vizcaino et al. 2016, Arroyas Langa y Pérez Díaz 2016).

A diferencia de lo que sucede con otros partidos de derecha radical populista, como con Nigel Farage o Geert Wilders, Abascal no parece encajar demasiado con el rol de líder carismático y personalista. Tras años militando en el Partido Popular, donde no consiguió una posición muy relevante, fundó Vox junto a otros compañeros del mismo partido. Hoy en día, Vox tiene un grupo de

${ }^{48}$ El País, "El mensaje completo de Pablo Iglesias en el que anuncia que deja el Gobierno", 15 marzo de 2021.

Araucaria. Revista Iberoamericana de Filosofia, Política, Humanidades y Relaciones Internacionales, año $23, \mathrm{n}^{\circ} 47$. Segundo cuatrimestre de 2021. Pp. 371-401. ISSN 1575-6823 e-ISSN 2340-2199 https://dx.doi.org/10.12795/araucaria.2021.i47.17 
líderes con un papel muy activo a nivel organizativo y de comunicación, como por ejemplo Javier Ortega Smith, Iván Espinosa de los Monteros, Macarena Olona, Jorge Buxadé y Rocío Monasterio. La presencia en redes sociales de Abascal es bastante importante, con 589 mil seguidores en Twitter y 817 mil en Instagram. En sus comunicaciones suele combinar elementos de su vida personal con un lenguaje emotivo y despectivo contra sus rivales (Sampietro y Sánchez-Castillo 2020).

El caso de los partidos independentistas es muy interesante por la transformación experimentada. Tradicionalmente el independentismo vasco no tuvo una figura visible que lo liderase. Sin embargo, después de la excarcelación de Arnaldo Otegi en 2016, tras seis años en prisión, este se ha convertido en el incontestable referente de la izquierda abertzale. A pesar de su pasado como miembro de la banda terrorista ETA, el independentismo vasco proyecta la imagen de que Otegi fue la figura clave para el cese de la violencia etarra. Él se autoproclama un "hombre de paz" y se llega a comparar con Mandela ${ }^{49}$.

Aunque el nacionalismo catalán ha tenido líderes personalistas como Jordi Pujol y Artur Mas, estos no pueden ser considerados globalmente populistas. El giro populista y secesionista fue impulsado por una gran variedad de políticos, periodistas, intelectuales y grupos de la sociedad civil. Sin embargo, tras el referéndum ilegal de independencia en Cataluña en 2017, que tuvo como consecuencia el encarcelamiento de algunos de sus dirigentes y la fuga de España de otros, este movimiento empiezó a dar muestras muy claras de culto a la personalidad de algunas de sus principales figuras y en especial de Carles Puigdemont, el líder de JxCat (Barrio et al. 2018: 1008; De las Heras Pedrosa et al. 2020: 15). A pesar de estar fugado de la justicia y no haberse presentado a las últimas elecciones, Puigdemont se ha seguido declarando presidente legítimo y controlando una parte importante del independentismo. Desde Bélgica ha intentado establecer una estructura paralela de poder, el Consell per la República, a través del cual se pretende arrogar poderes legislativos, ejecutivos y de representación exterior ${ }^{50}$. Por último, es importante destacar que Puigdemont es también una figura con una gran presencia y actividad en medios de comunicación y en redes sociales, con 793 mil seguidores en Twitter.

\section{Conclusiones}

El auge de líderes y partidos populistas por todo el mundo ha convertido este fenómeno en uno de los más debatidos actualmente. En España diferentes

\footnotetext{
${ }^{49}$ Teleberri, "Arnaldo Otegi, en ETB: la entrevista íntegra", 4 marzo de 2016; El País, "Arnaldo Otegi, el líder 'abertzale' que persiste", 19 diciembre 2020.

${ }^{50}$ El Periódico, "Consell per la República Catalana: Así funciona el mando paralelo de Waterloo", 24 marzo 2021.
}

Araucaria. Revista Iberoamericana de Filosofía, Política, Humanidades y Relaciones Internacionales, año $23, \mathrm{n}^{\circ} 47$. Segundo cuatrimestre de 2021. Pp. 371-401. ISSN 1575-6823 e-ISSN 2340-2199 https://dx.doi.org/10.12795/araucaria.2021.i47.17 
movimientos de cariz populista han adquirido visibilidad y cosechado buenos resultados electorales en los últimos tiempos. Por un lado, Podemos surgió como intento de canalizar políticamente el descontento ciudadano provocado por la Gran Recesión y construir una nueva mayoría social y hegemonía política para recuperar la soberanía, que las élites nacionales e internacionales habían, supuestamente, arrebatado al pueblo. Junto a Podemos, no solo nos encontramos a otros grupos populistas de izquierda radical -Catalunya En Comú o Más País-, sino también movimientos populistas de derecha radical, como Vox y otros de carácter secesionista: EH Bildu, ERC, JxCat y CUP. Este artículo ha mostrado que, a pesar de las más que significativas diferencias ideológicas y programáticas, todos estos partidos comparten muchas similitudes en la manera de articular sus comunicaciones, de interpretar las dinámicas sociales y políticas, así como de instrumentalizar las crisis para construir nuevas identidades políticas y obtener apoyos.

El concepto de populismo también ha suscitado grandes discrepancias dentro de las ciencias sociales. Nos encontramos así con diferentes escuelas o tradiciones que caracterizan el populismo bien como una ideología delgada, una estrategia política, una lógica de articulación discursiva o un estilo performativo. No obstante, a pesar de las relevantes divergencias teóricas, estos distintos enfoques son en gran medida complementarios y suelen reconocer la existencia de un núcleo de atributos comunes a la mayoría de los movimientos populistas. En este artículo se ha analizado el discurso de los partidos populistas en España utilizando un marco comparativo que disecciona este fenómeno en cinco dimensiones básicas: i) antagonismo, ii) moralidad, iii) construcción idealizada de la sociedad, iv) exaltación de la soberanía popular, y v) liderazgo personalista. Todas ellas aparecen en mayor o menor medida reflejadas en los discursos de los partidos analizados.

En primer lugar, todos estos grupos recurren a representaciones maniqueas de la sociedad donde enfrentan al "pueblo" contra un "otro". En el caso de Podemos este "otro" suele ser la "casta" y los partidos de derecha. Vox dirige su antagonismo contra inmigrantes, independentistas y la izquierda. Mientras tanto, el secesionismo considera al "Estado español" y sus instituciones como el principal enemigo. Todos ellos emplean una retórica hiperbólica y simplista, idealizando la confrontación y describiendo las dinámicas políticas mediante el uso de términos militaristas tales como "asalto", "reconquista", "invasión", "frente", "ocupación", entre otros muchos. Este antagonismo también se expresa en ataques a las instituciones que ellos pretenden abolir o reformar radicalmente. Mientras Podemos y el soberanismo cuestionan las credenciales democráticas del "regimen del 78" y se enfrentan a la monarquía, la justicia o las fuerzas de seguridad, entre otras instituciones, Vox propone la supresión de las televisiones públicas y órganos de gobierno autonómicos. 
Otra característica compartida es que estos partidos hacen una interpretación más moralista que programática de la política. En sus discursos enfatizan su superioridad moral respecto a sus rivales políticos, a quienes tratan constantemente de ridiculizar, demonizar y hasta deshumanizar. Más que criticar sus propuestas, centran los esfuerzos en descalificar a sus interlocutores, a los que se les trata de "corruptos", "criminales", "autoritarios" o "fascistas". Los líderes de estos partidos no solo reclaman superioridad moral, sino también el papel de víctimas. Además, estos partidos utilizan frecuentemente teorías conspirativas para deslegitimar al "otro". Aluden a tramas criminales en las que implican a políticos, empresarios y hasta periodistas y sugieren motivos ocultos y malas intenciones en las acciones de sus rivales. Se llega incluso a relacionar a estos con intentonas de golpe de estado y connivencia con el terrorismo.

La idealización de la sociedad e historia es una característica del populismo muy presente en estos partidos. Reinterpretaciones de la Edad Media, Segunda República, guerras civiles y la transición son usadas para construir el "pueblo" o la "nación", apuntalar relatos de humillación o exaltación patriótica y así deslegitimar o excluir al "otro". Se observan, no obstante, diferencias significativas entre estos grupos. Tanto Vox como los secesionismos catalán y vasco manifiestan un componente nativista que no está presente en Podemos. El discurso de Vox retrata España como una sociedad cristiana y relativamente homogénea que se ve amenazada por la inmigración, el islam y los separatismos. Mientras tanto el independentismo establece una distinción entre "verdaderos" vascos y catalanes y los españoles que viven en estas Comunidades Autónomas, a los que a veces se califica como "inmigrantes", "maketos", "coreanos", "charnegos", "ñordos" o "colonos". Estos partidos manifiestan concepción etnolingüística de la sociedad y aspiraciones irredentistas en sus proyectos de "Euskal Herria" y "Països Catalans". Por lo tanto, el componente de exclusión es mucho mayor en estos dos populismos que en Podemos.

La exaltación del pueblo y de la soberanía popular es un elemento también diferencial entre estos movimientos. Podemos y los partidos secesionistas apelan constantemente a la voluntad del pueblo, la necesidad de recuperar la soberanía perdida y al uso de herramientas de democracia directa, como referendums, asambleas ciudadanas o movilizaciones masivas. Vox, por su parte, adopta una posición más cercana al nacionalismo clásico en esta dimensión llamando a proteger la "soberanía nacional", con muchas menos referencias a la implicación directa de la ciudadanía en procesos decisorios. En todos ellos subyace una concepción "mayoritarista" de la democracia. En Podemos y el independentismo, se rechazan frecuentemente mecanismos de supervisión y control y la separación de poderes. Mientras, en Vox, se pretende excluir o limitar los derechos de ciertas minorías. 
También se pueden encontrar diferencias entre estos populismos en lo que respecta al tipo de liderazgo. Podemos, desde sus orígenes, asumió que era necesario un líder carismático que se mostrase próximo al pueblo y representase la unidad de éste. Pablo Iglesias se convirtió en ese líder personalista que gradualmente concentró un mayor poder. Aunque al igual que Iglesias, Santiago Abascal también utiliza un estilo desinhibido y agresivo, su liderazgo no parece ser ni tan personalista ni tan carismático. Por último, los independentismos vascos $\mathrm{y}$, sobre todo, catalán, han evolucionado de ser movimientos sin una clara figura visible que los liderase, a dar muestras muy claras de personalismo e incluso de culto a sus líderes.

En definitiva, este estudio hace patente cómo estos partidos comparten muchos de los rasgos ideacionales, discursivos y performativos que establece la literatura sobre populismo. Cabe también señalar algunas limitaciones de este estudio que invitan a profundizar en esta área de investigación. Este artículo ha esbozado algunos rasgos definitorios de los relatos del populismo en España, pero no ha cubierto la utilización de discursos populistas por partidos nopopulistas. De igual manera es importante recordar que los discursos populistas se adaptan al contexto específico y evolucionan, por lo que muchas de las narrativas anteriormente mencionadas puedes ser substituidas por otras. Así, por ejemplo, sería importante estudiar en más detalle la evolución del discurso de Podemos antes y después de entrar en el gobierno, la influencia de otros discursos de derecha radical en Vox, y las divergencias internas entre los relatos de construcción nacional y de pueblo de los distintos partidos independentistas.

\section{Fuentes de financiación y agradecimientos}

Esta investigación es parte del proyecto ICPPS (2018-T1/SOC-10152) financiado por el programa de atracción de talento investigador de la Comunidad de Madrid.

El autor quiere expresar su agradecimiento a todos los compañeros con los que colabora en diferentes aspectos de este proyecto sobre populismo y a los editores y coordinadores de este monográfico.

\section{Referencias bibliográficas:}

Alonso S. \& Rovira Kaltwasser C. (2015). Spain: No Country for the Populist Radical Right? South European Society and Politics, 20(1), 21-45.

Arato A. (2013). Political theology and populism. Social Research, 80(1): 143-172.

Arroyas Langa E. \& Pérez Díaz P.L. (2016). La nueva narrativa identitaria del populismo: un análisis del discurso de Pablo Iglesias (Podemos) en Twitter. Cultura, Lenguaje y Representación, 15, 51-63.

Anduiza E., Cristancho C. \& Sabucedo J.M. (2014) Mobilization through online social networks: The political protest of the Indignados in Spain. Information. Communication \& Society 17(6): 750-764. 
Barrio A., Barberà O. \& Rodríguez-Teruel, J. (2018). ‘Spain steals from us!' The 'populist drift' of Catalan regionalism. Comparative European Politics, 16(6), 993-1011.

Berlin I. (1968). To define populism. Government and Opposition, 3(2): 137-179.

Bonete Vizcaino F., Cebrián Guinovart E. \& Vázquez Barrio T. (2016). Pablo Iglesias' Tweeting Style: Unsuccessfully Aspiring to Renew Spanish Political Discourse. En Frame, A et al. (eds.) Tweets from the Campaign Trail, Frankfurt: PL Academic Research.

Brubaker R. (2020). Populism and nationalism. Nations and Nationalism 26(1): 44-66.

Canovan M. (1981). Populism. Londres: Junction.

Canovan M. (2002). Taking Politics to the People: Populism as the Ideology of Democracy. En Mény, Y. \& Surel, Y. (eds), Democracies and the Populist Challenge. Basingstoke: Palgrave Macmillan

Caramani D. \& Manucci L. (2019). National past and populism: the re-elaboration of fascism and its impact on right-wing populism in Western Europe. West European Politics, 42(6): 1159-1187.

Clua i Fainé M. (2011). Catalanes, inmigrantes y charnegos:'raza', 'cultura' y' mezcla' en el discurso nacionalista catalán. Revista de Antropología Social, 20, 55-75.

CUP (2015). Programa Polític Per Les Eleccions al Parlament de Catalunya del 27 de setembre de 2015. Candidatura d'Unitat Popular. Crida Constituent.

De las Heras-Pedrosa C., Jambrino-Maldonado C., Iglesias-Sánchez P. P., \& Millán-Celis E. (2020). Populism and Independence Movements in Europe: The Catalan-Spanish Case. Social Sciences, 9(4): 35.

De Nadal L. (2021). On populism and social movements: from the Indignados to Podemos, Social Movement Studies, 20(1): 36-56.

Deegan-Krause K. \& Haughton T. (2009). Toward a more useful conceptualization of populism: Types and degrees of populist appeals in the case of Slovakia. Politics \& Policy 37(4):821-841.

ERC (2017) Eleccions al Parlament 2017 Programa electoral la democràcia sempre guanya. Esquerra Republicana de Catalunya.

Errejón I., \& Mouffe C. (2015). Construir pueblo: hegemonía y radicalización de la democracia. Barcelona: Icaria.

Errejón I. \& Mouffe C. (2016). Podemos: In the name of the people. London: Lawrence \& Wishart.

Fernández-Albertos J., \& Lago I. (2015). Gobiernos autonómicos e identidades regionales en España, 1980-2012. Política y gobierno, 22(2): 283-315.

Franzé J. (2017). La trayectoria del discurso de Podemos: del antagonismo al agonismo. Revista Española de Ciencia Política, 44: 219-246.

Freeden M. (2017). After the Brexit referendum: revisiting populism as an ideology, Journal of Political Ideologies, 22(1): 1-11.

García Sanjuán A. (2020). Weaponizing Historical Knowledge: the Notion of Reconquista in Spanish Nationalism. Imago Temporis: Medium Aevum, 14: 133-162.

Gómez-Reino M. \& Llamazares I. (2019). Populism in Spain: The role of ideational change in Podemos. En K.A. Hawkins, R.E. Carlin, L. Littvay, \& C.R. Kaltwasser (eds.), The ideational approach to populism: Concept, theory, and analysis. Londres: Routledge.

Gómez-Reino M. \& Plaza-Colodro C. (2018). Populist Euroscepticism in Iberian party systems. Politics, 38(3), 344-360. 
Griffin, R. (1991). The Nature of Fascism. Nueva York: St Martin's Press.

Griffiths, R. D. \& Martinez A. (2020). Local conditions and the demand for independence: A dataset of secessionist grievances. Nations and Nationalism, 27(2): 580-590.

Hameleers M. \& Vliegenthart R. (2020). The rise of a populist zeitgeist? a content analysis of populist media coverage in newspapers published between 1990 and 2017. Journalism Studies, 21(1): 19-36.

Hawkins K.A. \& Rovira-Kaltwasser C. (2017). The ideational approach to populism. Latin American Research Review, 52(4): 513-528.

Hessel, S. (2011). Indignez-vous! édition revue et augmentée. Indigène éditions.

Homolar A. \& Löfflmann G. (2021). Populism and the Affective Politics of Humiliation Narratives. Global Studies Quarterly, 1(1)

Howarth D. \& Stavrakakis Y. (2002) Introducing Discourse Theory and Political Analysis. En D. Howarth, A. Norval and Y. Stavrakakis (eds.) Discourse Theory and Political Analysis: Identities, Hegemonies and Social Change, Manchester: MUP.

Iglesias Turrión P. (2015). Disputar la Democracia: Política para Tiempos de Crisis. Madrid: Ediciones Akal.

Ivaldi G., Lanzone, M.E. \& Woods, D. (2017). Varieties of populism across a left-right spectrum. The case of the Front National, the Northern League, Podemos and Five Star Movement. Swiss Political Science Review, 23(4): 354-376.

Jaffrelot C., \& Tillin L. (2017). Populism in India. En K.A Hawkins, R.E. Carlin,L. Littvay \& C. Rovira-Kaltwasser (eds). The Ideational Approach to Populism: Concept, Theory, and Analysis. Londres: Routledge.

Jagers J. \& Walgrave S. (2007). Populism as political communication style: An empirical study of political parties' discourse in Belgium. European Journal of Political Research, 46(3): 319-345

Junts Pel Sí (2015). Programa electoral Junts pel Si.

Junts Per Catalunya (2019). Programa Electoral. Eleccions al Congrés i al Senat - 28 d'abril de 2019.

Kazin M. (1998). The populist persuasion: An American history. Ithaca, NY: Cornell University Press.

Kim S. (2021). Taking stock of the field of populism research: Are ideational approaches 'moralistic' and post-foundational discursive approaches 'normative'. Politics, $10.1177 / 02633957211007053$

Krasteva A., \& Lazaridis G. (2016). Far right: Populist ideology, 'othering'and youth. In Ranieri, M. Populism, Media and Education. Londres: Routledge.

Kriesi H., Grande E., Lachat R., Dolezal M., Bornschier S. \& Frey T. (2008). West European politics in the age of globalization. Cambridge: CUP.

Kriesi H. (2018). Revisiting the populist challenge. Politologický časopis-Czech Journal of Political Science, 25(1): 5-27.

Kyriakidou M. \& Olivas Osuna J.J. (2017). The indignados protests in the Spanish and Greek press: moving beyond the 'protest paradigm'? European Journal of Communication, 32(5): 457-472.

Laclau E. (2005a). La razón populista. México DF: Fondo de Cultura Económica.

Laclau E. (2005b). Populism: What's in a Name? En F. Panizza (ed.) Populism and the Mirror of Democracy. Londres: Verso.

Laclau E. \& Mouffe, C. (2001). Hegemony and Socialist Strategy: Towards a Radical Democratic Politics, 2nd ed. Londres: Verso. 
Lebow D. (2019). Trumpism and the dialectic of neoliberal reason. Perspectives on Politics, 17(2): 380-398.

López Romo R. \& Fernández Soldevilla G. (2018). From ethnic exclusion to terrorism? The case of radical Basque nationalism. Journal of Iberian and Latin American Studies, 24(3): 443-459.

Mansvelt Beck J. (2006). Geopolitical imaginations of the Basque homeland. Geopolitics, 11(3), 507-528.

Meijers M.J. \& Zaslove, A. (2020). Populism and Political Parties Expert Survey 2018 (POPPA), 10.7910/DVN/8NEL7B, Harvard Dataverse.

Moffitt B. (2015). How to perform crisis: A model for understanding the key role of crisis in contemporary populism. Government and Opposition 50(2): 189-217.

Moffitt B. (2016). The global rise of populism: Performance, political style, and representation. Stanford: SUP.

Moffitt B. \& Tormey S. (2014) Rethinking Populism: Politics, Mediatisation and Political Style. Political Studies, 62(2): 381-397.

Moreno-Almendral R. (2018). Nation, people and 'national populisms in contemporary Spain’. En F. López Alves \& D.E. Johnson (eds.) Populist Nationalism in Europe and the Americas. Londres: Routledge.

Mouffe C. (2018). For a left populism. Londres: Verso Books.

Mudde C. (2004). The Populist Zeitgeist. Government and Opposition, 39(4): 542-563.

Mudde C. \& Rovira Kaltwasser C. (2018). Studying populism in comparative perspective: Reflections on the contemporary and future research agenda. Comparative Political Studies, 51(13): 1667-1693.

Müller J.W. (2014). The people must be extracted from within the people: Reflections on populism. Constellation, 21(4): 483-493.

Müller J.W. (2016). What is Populism? Filadelfia: University of Pennsylvania Press

Newth G. (2021). Populism and nativism in contemporary regionalist and nationalist politics: A minimalist framework for ideologically opposed parties. Politics, $10.1177 / 0263395721995016$

Norris P. (2020) Measuring Populism Worldwide. Faculty Research Working Paper Series. Febrero 2020, Harvard Kennedy School.

Olivas Osuna J.J. (2017). Does the Catalan independence movement really 'love democracy'? Euro Crisis in the Press (14 Jun 2017).

Olivas Osuna J.J. (2019). Deconstructing and Comparing Populism: The Cases of SNP and Catalan Independence Parties. Working Paper. Presentado en American Political Science Association 2019 Annual Meeting, 29 agosto 2019.

Olivas Osuna J.J. (2020). Populism in Borders. Working Paper. Presentado en European Sociological Association (ESA) 2020 Conference, 30 octubre 2020.

Olivas Osuna J.J. (2021). From chasing populists to deconstructing populism: a new multidimensional approach to understanding and comparing populism. European Journal of Political Research. 10.1111/1475-6765.12428

Olivas Osuna, J.J. \& Rama J. (2021). COVID-19: a political virus? VOX's populist discourse in times of crisis, Frontiers in Political Science, 10.3389/fpos.2021.678526

Oller J.M., Satorra A. \& Tobeña A. (2019). Secessionists vs. Unionists in Catalonia: mood, emotional profiles and beliefs about secession perspectives in two confronted communities. Psychology, 10(3): 336-357. 
Ostiguy P. (2009). The high-low political divide: rethinking populism and anti-populism. Committee on Concepts and Methods Working Papers Series Political Concepts, 35.

Ostiguy P. (2017). A Socio-Cultural Approach. In Rovira-Kaltwasser, C., Taggart, P. Ochoa-Espejo, P. \& Ostiguy, P. (eds), The Oxford Handbook of Populism. Oxford: Oxford University Press.

Ostiguy P \& Moffitt, B. (2021). Who Would Identify With An 'Empty Signifier'? In Ostiguy P., Panizza F., \& Moffitt B. (eds.). Populism in Global Perspective: A Performative and Discursive Approach. Nueva York: Routledge.

Panizza F. (2005). Populism and the Mirror of Democracy. Londres: Verso.

Pappas, T.S. (2019). Populism and Liberal Democracy: a Comparative and Theoretical Analysis. Oxford: Oxford University Press.

Pérez-Nievas S., Rama-Caamaño J., \& Fernández-Esquer, C. (2018). New Wine in Old Bottles? The Selection of Electoral Candidates in General Elections in Podemos. En Cordero G. \& Coller X. (eds) Democratizing Candidate Selection. Cham: Palgrave Macmillan.

Pirro A.L., Taggart P. \& Van Kessel S. (2018). The populist politics of Euroscepticism in times of crisis: Comparative conclusions. Politics, 38(3): 378-390.

Podemos (2016). Queremos, Sabemos, Podemos: Un Programa para Cambiar Nuestro País. Elecciones Generales 26 junio 2016.

Podemos (2019). Programa de Podemos para un nuevo país. Elecciones Generales 28 abril 2019.

Portos M. (2020). Europe in the Procés: European (dis-) integration and Catalan secessionism. European Journal of Cultural and Political Sociology, 7(3): 265-290.

Prentoulis M. \& Thomassen L. (2013). Political theory in the square: Protest, representation and subjectification. Contemporary Political Theory, 12(3): 166-184.

Ramiro L. \& Gómez R. (2017). Radical-left populism during the great recession: Podemos and its competition with the established radical left. Political Studies 65(1_suppl): $108-126$.

Rico G., Guinjoan M. \& Anduiza E. (2017). The emotional underpinnings of populism: How anger and fear affect populist attitudes. Swiss Political Science Review, 23(4): 444-461.

Roberts, K. (2007). Latin America's populist revival. SAIS Review of International Affairs 27(1): 3-15.

Roberts K. (2015). Populism, political mobilizations, and crises of political representation. En C. de la Torre (ed.) The Promise and Perils of Populism. Lexington: The University Press of Kentucky.

Roberts K. (2019). Crises of Representation and Populist Challenges to Liberal Democracy. Chinese Political Science Review, 4(2): 188-199.

Rueda Laffond J.C. (2016). El Candado del 78: Podemos ante la Memoria y la Historiografía sobre la Ruptura Democrática. Historia Contemporánea, 53: 725-751.

Ruiz Casado J. A. (2020). Articulations of populism and nationalism: The case of the Catalan independence movement. European Politics and Society, 21(5): 554-569.

Sampietro A \& Sánchez-Castillo S. (2020). La promoción de la imagen política en Instagram: un estudio del perfil personal de Santiago Abascal (Vox) en 2018. Communication \& Society, 33(1): 169-184.

Sartori G. (1970). Concept Misformation in Comparative Politics. American Political Science Review, 64(4), 1033-1053. 
Simon H.A. (1972). Theories of bounded rationality. Decision and Organization, 1(1): 161-176.

Stanley B. (2008). The Thin Ideology of Populism. Journal of Political Ideologies, 13(1): 95-110.

Taggart P. (2000). Populism. Buckingham: Open University Press.

Taguieff P.A. (1984). La rhétorique du national-populisme: Les règles élémentaires de la propagande xénophobe. Mots, 9: 113-139.

Tăranu A. (2012). Populism as the 'democratic malaise'. European Journal of Science and Technology 8(suppl. 1): 131-141.

Turnbull-Dugarte S.J. (2019). Explaining the End of Spanish Exceptionalism and Electoral Support for Vox. Research and Politics, 10.1177/2053168019851680.

Ucelay-Da Cal E. (2013). History, historiography and the ambiguities of Catalan nationalism. Studies on National Movements, 1:105-159.

Urbinati N. (2014). Democracy disfigured. Opinion, truth, and the people. Cambridge: Harvard University Press.

Vallespín F. \& Martínez-Bascuñán M. (2017). Populismos. Madrid: Alianza Editorial.

Vampa D. (2020). Competing forms of populism and territorial politics: the cases of Vox and Podemos in Spain. Journal of Contemporary European Studies, 28(3): 304-321.

Vasilopoulou S., Halikiopoulou D. \& Exadaktylos, T. (2014). Greece in Crisis: Austerity, Populism and the Politics of Blame. JCMS, 52(2): 388-402.

Vox (2019a). Programa electoral para las elecciones europeas de 2019. Manifesto for European Elections.

Vox (2019b). 100 medidas para la España Viva. Manifesto for general elections in 2019.

Weyland K. (2001). Clarifying a contested concept: Populism in the study of Latin American politics. Comparative Politics 34(1): 1-22.

Weyland K (2020) Populism's Threat to Democracy. Perspectives on Populism, 18 (2): 389-406.

Wiles P. (1969). A Syndrome, Not a Doctrine: Some Elementary Theses on Populism. In Ionescu, G. y Gellner E. (eds) Populism - Its Meanings and National Characteristics. Londres: Weidenfeld and Nicolson.

Wodak R. (2015). The Politics of Fear: What Right-Wing Populist Discourses Mean. Londres: SAGE.

Zaslove A. (2011). The re-invention of the European radical right: Populism, regionalism, and the Italian Lega Nord. Kingston: MQUP. 
